that with far more delicate arrangements than a hen provides, the results obtained by the use of the incubator do not always equal those given by the sitting hen. He concludes that an incubator which will do all that the best hen does and do it regularly and with certainty, is a perfectly realisable instrument. He gives very full details of the physical and biological factors involved in incubation, drawn largely from the results of his own experimentation, and the conditions underneath the sitting hen are compared in detail with those that exist within the various types of standard incubators. The outstanding conclusions at which he arrives are that practically every type of incubator has the air too dry; that the average temperature of the eggs in an incubator is much more regular than in a hen's nest; and that, whereas in modern incubators the whole of the egg is nearly of the same temperature, the temperature of the top being only slightly different from that of the bottom, in the hen's nest the difference between the temperature of the hen's body in contact with the egg and the temperature of the lower surface of the egg is between $14^{\circ}$ and $20^{\circ} \mathrm{F}$.

From these observations the author concludes that the secret of successful incubation lies in keeping the upper surface of the egg hot and the lower surface relatively cool. This object is attained by covering the upper surface of the eggs with a very thin sheet of india-rubber. The use of this in a hot water incubator, in which the heat reaches the eggs by radiation, is rendered extremely difficult by the fact that the temperature of the tank has to be raised to a most inconvenient degree. In the case of the hot air type of incubator, however, it is quite simple to get a difference of $14^{\circ} \mathrm{F}$. between the top and the bottom of the egg by the use of this rubber sheet. It was found also that with this method rapid evaporation of moisture was prevented and that, in fact, the amounts of moisture and carbonic acid around the eggs were nearly those present in a hen's nest. Using this method, an incubator which previously had rarely given more than 55 per cent. hatched more than 95 per cent. of the fertile eggs. It is to be noted that the application of heat to the eggs is by direct contact and conduction instead of by radiation or convection. Every egg becomes its own regulator, controlling the passage of the heat from the upper surface of the egg to the cooler under surface. Mr. Atkinson states also that the chicks emerging from an incubator provided with this rubber sheet are far more viable.

\section{The Blue Whale.}

MR. GERRIT S. MILLER'S paper, " Some $M$ hitherto unpublished photographs and measurements of the Blue Whale" (Proc. U.S. Nat. Mus., Vol. 66, pp. I-4, Pls. i.-ix.) is a welcome contribution to the literature of Cetacea. In spite of its predominating importance to modern whalers, the blue whale (Balcenoptera musculus) is still imperfectly known, particularly with regard to cranial characters. Mr. Miller publishes specially good figures of the skull, the rostrum of which has not suffered from the warping which commonly occurs on drying. $\mathrm{He}$ informs us that the specimen (Washington Museum) was an adult male, 75 feet long, captured off Newfoundland in I903; but it may be remarked that the free condition of the distal epiphyses of the radius and ulna figured in Pl. viii. is evidence that the animal had not completely passed the adolescent stage of Flower, and that in any case 75 feet is a small measurement for a really adult blue whale. The digits shown in the same figure appear to be too straight, and the hand is probably a reconstruction of a disarticulated flipper, as indicated by the fact that the numbers of the phalanges are low as compared with other records.

Mr. Miller makes no comparisons, and his facts must speak for themselves. With regard to the skull, the rostrum deserves special notice, its sides being parallel in its posterior half, then converging in a gentle curve to the tip; - in striking contrast with the triangular, straight-sided rostrum of the fin whale (B. physalus). The premaxillæ are noticeably parallel behind, instead of being arched outwards. The postero-internal processes of the maxillæ are long, the orbital plates of the frontals diminish greatly in diameter in passing outwards, and the nasals are stout and broad. The palatines have parallel sides, and in the side view the straight outer edge of the maxilla and the outline of the vertex are other features in which this skull differs from that of a fin whale. Excellent figures are given of the atlas, axis, sternum, pelvic bones and scapula, the last showing the restored cartilaginous parts. As bearing on the great variability of the bones in the larger Cetacea it may be noticed that the sternum differs conspicuously from those figured by True in 1904, as well as from that of the Longniddry whale described by Turner. The long series of measurements of bones will be valuable as material for comparison with southern blue whales, the identity or otherwise of which with the northern species it will be the special object of the Discovery expedition to investigate.

S. F. H.

\section{University and Educational Intelligence.}

BRISTOL.-A research assistantship is open at the Merchant Venturers' Technical College to candidates with an honours degree in engineering. Applications should be made to Prof. A. Robertson at the College.

CAmbridge.-Mr. Arthur Berry has been elected vice-provost of King's College. A new post of assistant director of magnetic research at the Cavendish Laboratory, without stipend from the University, has been established for Dr. P. Kapitza, Trinity College.

By a recent vote of the Senate, the University is to ask the Commissioners to remove from the statutes the paragraph under which certain holders of official positions, such as bishops, heads of house, and privy councillors, can at present be granted degrees honoris causa in virtue of the positions that they occupy. University and college teachers and officers are still to be eligible for the degree of Master of Arts, and the University retains its powers to grant honorary degrees to members of the Royal Family, to British subjects who are of conspicuous merit or have done good service to the State or to the University, and to foreigners of distinction.

Dr. Haddon is resigning from the readership in ethnology.

The vice-chancellor, Dr. Fitzpatrick, president of Queen's College; Dr. Giles, master of Emmanuel College; Mr. F. J. M. Stratton, Gonville and Caius College; and Mr. R. E. Priestly, Clare College, have been appointed delegates at the coming conference of the universities of Great Britain and Ireland.

Sir R. H. Biffen, St. Catharine's College; Mr. R. Adie, Trinity College; Mr. F. L. Engledow and Mr. C. W. B. Wright, St. John's College, have been appointed to represent the scientific workers on the Station Committee of the Horticultural Research Station, while Messrs. W. P. Seabrook, A. G. Daniels, and A. T. Paskett represent the fruit and vegetable growers. 
Notice has been given that an election will be made next July to the Charles Abercrombie Smith Studentship of I5ol. a year at Peterhouse. Every candidate must be or must become a research student, proceeding to the degree of Ph.D. The studentship is normally for two years and may be renewed in exceptional circumstances for a third year.

Durham.-The seventh Earl Grey memorial lecture will be delivered at Armstrong College on Thursday, March 5 , at $7 \cdot 30$, by Dr. F. W. Aston, on "The Structural Units of the Material Universe."

Applications are invited for the professorship in botany at Armstrong College. The latest date for the receipt of applications (in each case ten copies) is May I5. They should be sent to the Registrar of the College, Newcastle-upon-Tyne.

LoNDoN.-The two following courses of free public lectures at the Royal School of Mines are announced : "Chemical Combination in Metallic Alloys and its Nature," by Prof. C. A. Edwards, at 5.30, on March 3, 4 , IO, and II; and " Tubbing Deep Shafts" and "Subsidence," by Prof. L. Denoël, at 5.I5, on March I6, I7, I8, and I9. Free public lectures will be delivered at University College as follows: on March 4, II, and r8, "Nutrition of the Young Animal," by Prof. T. B. Wood, and on March 9 and II, "Vital Statistics," by Prof. H. Westergaard. The lecture hour in each case will be $5 \cdot 30$.

Manchester.-Messrs. Brunner, Mond and Co., Ltd., have continued their grants in aid of research in the Departments of Physics and Chemistry.

The Council has adopted regulations for the award of the Philip Buckle Research Scholarship in agricultural zoology. This scholarship has been endowed in memory of the late Philip Buckle by his brothers and sisters.

Mr. J. C. Oakden has been appointed assistant lecturer in mechanical engineering in the Faculty of Technology.

THE City of Cardiff Education Committee will shortly appoint a head of the department of physics of the Cardiff Technical College. Applicants for the post should send 20 copies of their applications and testimonials on or before Saturday, February 28, to the Principal of the College.

Applications are invited by the Manchester Municipal College of Technology for the position in the college of lecturer in the chemistry of fermentation processes. Particulars of the appointment and a form of application may be obtained from the Registrar. The latest date for the return of the completed form is March $\mathrm{r}_{4}$.

THE Commonwealth Fund, I East 57th Street, New York, was founded in I9r 8 by Mrs. Stephen V. Harkness " to do something for the welfare of mankind " and is a philanthropic institution which has already made some noteworthy gifts. It is now announced that twenty fellowships a year in American universities, each of the value of about $600 l$, , have been established for British graduates by the Fund. The fellowships will be tenable for two years, and election will be by a committee of award consisting of Sir Walter Robert Buchanan-Riddell, Bt., Principal of Hertford College, Oxford (chairman); Sir Hugh Kerr Anderson, Master of Gonville and Caius College, Cambridge; Sir James Colquhoun Irvine, Principal of the University of St. Andrews; Sir Theodore Morison, Vice-Chancellor of the University of Durham; and Prof. T. Percy Nunn, Principal of the London
Day Training College. The Prince of Wales has consented to become honorary chairman of the committee. The general object of the fellowships is to promote international goodwill and generally to foster unity of thought and purpose in the United States and Great Britain. The awards will therefore be made on the basis of character, ability for leadership, health and general fitness, and on the nomination of recognised universities of Great Britain and Ireland.

Mr. H. Simpson GeE, of Knighton Frith, Leicester, who died last July, bequeathed to University College, Leicester, of which he was honorary treasurer, 20,oool. free of all duties, to found " The Simpson Gee Endowment Fund." Under the provisions of the will the executors could have deferred payment of the legacy for three years, but they generously offered to discharge the legacy forthwith and give the College the option of taking over certain specified securities of a full trustee character at the "market price" of the day. This offer the College Council gratefully accepted, and as a consequence trustee stocks of this value have been transferred, by which the endowment income of the College has been augmented by $980 \mathrm{ol}$. per annum. Other gifts recently received are :-200o $l$. from Sir Jonathan North, chairman of the College Council (by which his donation to the General Endowment Fund has been brought up to $5000 l$.), and $3000 l$. from Messrs. Stead and Simpson, Ltd., to the fund for endowing lectureships in chemistry and physics. Leicester University College, although brought into existence in r92I during the post-War economic depression, has, nevertheless, in addition to the finest site in Leicester, on the top of the city, and large and beautiful buildings and college gardens, valued at I 5o,oool., obtained an invested endowment fund which has just completed its first 100,00ol. In addition, it receives an annual grant from the city of Leicester. By the beginning of next academic year, it will have teachers in all the main subjects of university study, unusually adequate equipment in laboratories, and a library of 9000 volumes.

THE annual distribution of prizes was held at the Sir John Cass Technical Institute, Aldgate, London, E.C.3, on Tuesday, February Io, when the prizes and certificates were distributed by $\mathrm{Mr}$. S. O. Nevile, past-president of the Institute of Brewing. The chairman of the governing body, the Rev. J. F. Marr, in giving a summary of the work of the Institute, stated that although the courses of study at the Institute are principally conducted in the evenings, no fewer than 36 students were successful at the examinations of the University of London during the past session, two of whom obtained the degree of Ph.D., and three the degree of M.Sc., by research. In addressing the students, Mr. Nevile stated that institutes such as the Sir John Cass Technical Institute supply two urgent needs of modern industrialism : they offer opportunities for advanced scientific education and training in research, and they enable those engaged in the minor ranks of industry to obtain a knowledge of the principles which underlie their daily work and a broader conception of their industry as a whole. The technology of brewing comprises-first, the production of the raw materials; secondly, the treatment of those raw materials to provide a satisfactory extract; and thirdly, the process of fermentation itself. Pasteur must be regarded as the father of the modern conception of fermentation as applied to the brewing and wine industries. Our knowledge of hops and barley is still very incomplete, and the research scheme of the Institute of Brewing is largely concentrated on these two main fundamental issues. 